\title{
"Moving out of the safe zone": Promoting learning communities and reflective supervision in a social work statutory child protection agency
}

\author{
Matt Rankine and Andrew Thompson, University of Auckland, Aotearoa New Zealand
}

\begin{abstract}
INTRODUCTION: Social work supervision in statutory child protection settings is often confused with line management and has little focus on professional development, critical reflection and exploration of practice. Within Aotearoa New Zealand, the statutory child protection agency Oranga Tamariki (OT), is under considerable scrutiny regarding the management of risk, child abuse, and the over-representation of Māori tamariki within the child welfare system. This article covers the first collection of findings from a larger supervision study.

METHODS: Using critical reflection as the methodological lens, four experienced OT supervisors participated in a learning community where supervision recordings were brought to each meeting to improve reflective capacity, critical reflection and skills. Data were collected from the learning community and thematic analysis was undertaken to explore current supervision practice in OT.

FINDINGS: The three themes generated from the learning community discussions were: supervisory skills/interventions; the structure of supervision; and working with emotion and trauma. These themes highlighted the significance of the learning community as a forum for supervisors to share their existing supervision practice together, "moving out of the safe zone" as they engaged in positive and constructive feedback with their colleagues in a supportive space.
\end{abstract}

CONCLUSIONS: Reflective supervision, within statutory child protection, is essential for learning, critical reflection and cultivating robust decision making in social work practice. The creation and development of professional supervision spaces such as learning communities provide the basis for supervisors and supervisees to develop their skills and ensure accountable, anti-oppressive and ethical practice.

KEYWORDS: Supervision; social work; critical reflection; learning communities; professional practice

AOTEAROA NEW ZEALAND SOCIAL WORK 33(2), 88-103.

CORRESPONDENCE TO: Matt Rankine

m.rankine@auckland.ac.nz
Globally, there is a need to explore social work supervision in different contexts, and particularly in the child protection field (Carpenter et al., 2012). Social work supervision can be caught between the competing pressures of professional and organisational accountabilities within a managerial climate of risk and outcome measures. Within this difficult climate, it is essential for social workers to develop a 
critical understanding of their practice with service users. In addition, the supervisor needs to have specialist knowledge in the delivery of reflective supervision (Rankine, 2017).

The context of the research is the Aotearoa New Zealand statutory care and protection agency, Oranga Tamariki (OT). The agency has been under considerable scrutiny due to the over-representation of tamariki Māori (children) being uplifted from their whānau (family). The procedures and legislation governing the agency have been criticised in reports from the Ombudsman (Boshier, 2020), the Office of the Children's Commissioner (OCC, 2020) and the Waitangi Tribunal (Waitangi Tribunal Report, 2021). All the reports identified deficits in the delivery of reflective supervision.

The OCC (2020) called for urgent changes to "strengthen and implement existing recruitment, retention, mentoring and supervision policies and practices that address interpersonal, institutional and structural racism and support staff to work effectively with pēpi Māori, their whānau, hapū and iwi" (p. 86). The Ombudsman also called for urgent changes following review of 74 newborn (and unborn) infants after OT applied for interim custody under section 78 of the Oranga Tamariki Act 1989 during the period between 1 July 2017 and 30 June 2019. “In 46 percent of cases, there was no evidence of professional supervision. Where there were records of professional supervision, 90 percent of these were focused on tasks, actions and next steps, rather than the required critical and reflective practice" (Boshier, 2020, p. 21).

It was within this current backdrop that the authors engaged in a research project with social work supervisors and supervisees at OT to explore current reflective supervision practices and strengthen practitioner development. The focus of the research was to explore ways to generate life-long learning, greater resilience, self-awareness and develop practices that support reflective capability and well-being amongst supervisors and supervisees. To explore these areas, the research comprised of three separate aspects: a supervisor's learning community; supervisor-supervisee dyads; as well as a pre- and post-intervention online survey.

This article focuses on one branch of that research, the development of a learning community with four OT supervisors. The findings from the supervisor-supervisee dyads and online survey are to be published elsewhere in social work journals. Within this context, the positioning of supervision is key to developing high quality practice and, ultimately, improving outcomes for tamariki and their whānau. The aim of the learning community, in alignment with the focus of the research outlined above, was to deepen the reflective capacity of the supervisors and create a space to critically reflect on skills and interventions used in supervision practice.

Engaging in a learning community of peers requires a high level of trust and a preparedness to be vulnerable. "Moving out of the safe zone" was a telling quote from a supervisor in the learning community. Experiential learning requires active involvement, reflection upon practice, conceptualisation of the experience, and integration of knowledge gained from the experience (Knowles, 1990; Kolb, 2014). Moving out of the safe zone recognises the shift into a learning space that may, at times, be uncomfortable and challenging. The traditional notion of a learning curve is extended by evaluation and feedback from peers that stretches the learner beyond their comfortable space and supports growth.

\section{Defining social work supervision}

Supervision is a professional process where the supervisor is responsible for the supervisee, with the intent of meeting organisational and administrative agendas, as well as personal and professional goals (Morrison, 2001). For the social worker, 
supervision has become an integral and lifelong part of practice across all fields of work (Davys \& Beddoe, 2020). Within the last decade, the social work supervision literature has grown, with academics, practitioners, managers and policy makers all accepting that supervision is a core ingredient for high-quality social work practice (Wilkins et al., 2017). It is a regulatory and mandatory obligation in many jurisdictions, including Aotearoa New Zealand. Supervision in social work assists with the development of self-care (Rankine, 2017), resiliency (Beddoe et al., 2014), professional development (Nickson et al., 2020) and the reduction of stress and burnout (Carpenter et al., 2012; Mor Barak et al., 2009).

Supervision is at the heart of social work and should include reflection and critical reflection. Reflection is learning from past experiences, re-considering beliefs and perspectives in order to develop future actions (Kolb, 2014; Noble et al., 2016). It is vital that social workers can reflect, learn, re-imagine, assess and grow as professionals through reflection and incorporate this process in their practice. Critical reflection provides a social worker with the opportunity to question beliefs, distortions in thinking, and examine structures in the environment (Noble et al., 2016; Rankine, 2018). In addition, critical reflection assists social workers to identify and action alternative ways of practising (Fook \& Gardner, 2007). Fook and Gardner (2007) have highlighted a twostage process to critical reflection of, firstly, deconstructing beliefs and then reconstructing practice with further action strategies. Reflective supervision encompasses all these definitions and is a professional activity with accountability to professional and organisational standards (Davys \& Beddoe, 2020).

\section{Supervision in statutory child protection organisations}

Child protection social work is challenging and demanding (Davys \& Beddoe, 2020) and there can be negative impacts on social workers' psychological well-being (Bradbury-Jones, 2013). Within this setting, social workers require advanced skills in complex decision-making to manage the levels of bureaucracy and the realities of child abuse (Kelly \& Green, 2019). Davys and Beddoe (2020) have highlighted three factors influencing reflective supervision in this environment:

a. risk discourses of blame;

b. lack of existing skills and courage to explore uncertainty and ambiguity; and

c. professional values and relationships replaced by technological systems.

The supervisor endeavours to fulfil their administrative requirements through enforced procedures nested within data management systems and managing risk. Not surprisingly, the common focus in child protection supervision is case discussion. The social work supervisee is commonly supervised by their line manager who provides oversight, performance management and organisational accountability for the social worker's practice (Baginsky et al., 2010). The high level of organisational risk associated with child protection, and the accompanying media, public scrutiny and abuse, have subjected child protection social workers to neoliberal and managerial agendas (Beddoe, 2010). Consequently, social workers strive to empower families and protect children in a cost-effective and time-focussed manner whilst often managing unrealistic caseloads, dwindling resources and staffing cutbacks (Hyslop, 2017).

These systemic pressures and expectations within child protection work can leave little room for emotional support, reflection and critical reflection (Wilkins et al., 2017).

Over a decade ago, O’Donoghue (2008) identified that social work supervision needs to promote professional and client-led practice. These issues are still relevant today 
as evidenced by the OCC and Ombudsman reports where exploring uncertainty and ambiguity in social work practice were seen as needing to be addressed. The supervision space has become cluttered with organisational requirements and obligations that take priority over individual social worker's time and space for critical reflection.

Striving to provide a quality social work service and a more sustainable workforce, OT has recently developed changes.

The changes have seen the promotion of a Professional Supervision Policy and Standards-a commitment to improve social workers' skills and knowledge through quality supervision that is committed to improving outcomes for children and families (Oranga Tamariki, Ministry for Children [OT], 2017). The policy outlines the expected outcomes from supervisors that include the promotion of reflection and critical reflection as key in developing practitioners, as well as the need to participate in their own ongoing professional development (OT, 2017). Whilst the policy itself is a positive step forward, the implementation and any changes made in supervision continue to be problematic, especially in assessing impacts on decision making and outcomes for Māori (Waitangi Tribunal, 2021).

\section{Developing supervisors and their supervision of others}

In Aotearoa New Zealand over the last two decades, supervision practice has been consolidated with recognition of its importance through training providers and social service institutions (O'Donoghue \& Tsui, 2011). The Aotearoa New Zealand Association of Social Workers (ANZASW) and the Social Workers Registration Board (SWRB) have highlighted the significance of social work supervisors and need for specialised supervision training (Beddoe, 2016). A national study by Beddoe et al. (2012) linked poor supervision, as identified by practitioners, with a lack of qualifications and knowledge in their supervisor. Other studies, in the United Kingdom, such as Wilkins et al. (2017) have also detected that, in statutory child protection, a greater focus is placed on training social workers than the development of supervisors.

Within the current managerial context, supervisors need to be supported to develop and hone their skills (Rankine, 2017).

Safe, ethical and accountable supervisory practice can then take place. As an initial step towards evaluating current supervision practises, supervisors may seek feedback from their supervisees. Within the current climate, however, feedback may be relatively ad hoc and informal (Davys et al., 2017). Finding more effective ways of evaluating and reviewing existing supervision is highly advantageous to developing practice (Wilkins et al., 2018).

Recording supervision sessions provides a good source of information and feedback for supervisors for development purposes (Bernard \& Goodyear, 2009). This approach has been used in supervision training (Davys \& Beddoe, 2020) and has been recommended to assist reflection on practice for experienced professionals regarding the supervisory relationship, expectations and roles (Hill et al., 2016). Davys et al. (2019) developed a supervisors' learning community where the goal was "to share practice in a safe environment, to reflect critically on the practice, to receive feedback and to build supervision competence" (Davys et al., 2019, p. 4). The authors concluded that, through collaborative enquiry, a learning community promoted critical reflection and learning, and was a key element in developing supervisor competence.

\section{Methodology}

Social constructionism and critical realism are the epistemological standpoints related to this research and define how knowledge, meaning and phenomena are explained by participants (Crotty, 1998). Social 


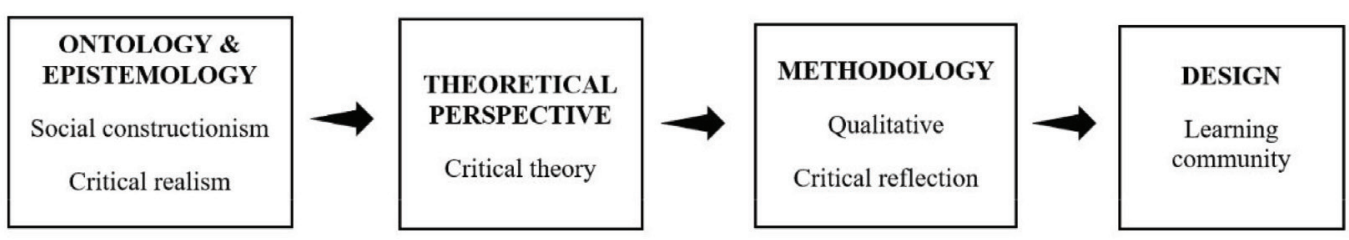

Figure 1. The Methodological Approach of the Study

constructionism focuses on how context influences people's understandings of self, others and the world around them (Crotty, 1998). Critical realism identifies dominant social structures as central to shaping causal explanations (Bhaskar, 1979). Critical realism also encourages the use of critical approaches in qualitative research and the co-construction of knowledge between participants in practice (see Figure 1).

Critical theory identifies oppression at individual and structural levels, explores alternative approaches (Fook \& Gardner, 2007) and accommodates critical reflection (Baines, 2017). Critical reflection, positioned as a research methodology (Fook, 2011), enables the conceptualisation of practice experience in context and is recognised as an effective tool for collecting and engaging with information, developing knowledge and promoting change (Ruch et al., 2015). This action research (Munford \& Sanders, 2008) allows researchers to become immersed in the study, working collaboratively with participants in a coconstructed research process (Morley, 2013). The authors, with extensive experience in reflective supervision, worked alongside experienced OT supervisors to explore and deepen reflective practice.

\section{The learning community}

Stoll et al. (2006) describe a learning community as "a group of people sharing and critically interrogating their practice in an ongoing, reflective, collaborative, inclusive, learning-oriented, growthpromoting way" (p. 223). In this study, four supervisors from an OT regional office in Aotearoa New Zealand explored whether a learning community increased their reflective capacity and promoted personal growth, learning and development. The learning community was established as a forum to improve reflection and supervision skills for the supervisors.

A regional OT office volunteered to participate in the research. Participants were invited to become involved through the distribution of an information sheet to all staff at the OT office. Participants, including supervisees who were audio recorded, voluntarily completed and returned signed consent forms. Participants chose pseudonyms and all identifying participant and client information was removed. In addition, the participants signed a group agreement regarding group rules and confidentiality at the commencement of the learning community.

The group of experienced supervisors had worked together for approximately 20 years, had several years' supervisory experience each and attended various supervision programmes which created many advantages for the learning community. We noted a high level of rapport and trust that facilitated active participation, honest feedback and a respectful, supportive environment.

The learning community sessions ran over a six-month period at the participants' office (about one 90-minute session per month). The sessions were facilitated and audiorecorded by the authors and transcribed by a professional transcriber. The authors ensured that the structure of the sessions and a process of critique and feedback (as described by Davys et al., 2019) were followed. This allowed two supervisors to separately present a selected audio segment 
from their supervision recordings each session (see Table 1).

The supervisors' recordings of the supervision sessions were used to promote critical reflection and to encourage the deconstruction of the supervision practice. Reconstruction of practice, through the introduction of new strategies and insight from others, has been described by Fook and Gardner (2007). In this research, within the learning community, supervisors were able to listen, consider and comment on their own supervision practice, but also actively engage in feedback with others.

\section{Ethical considerations}

The research was approved by the Human Participants Ethics Committee of the
University of Auckland. The authors sought written consent from the Chief Executive of Oranga Tamariki, the Senior Advisor of Regional Operations and the Regional Manager of the Oranga Tamariki site where the research was undertaken.

\section{Data analysis}

Thematic analysis, which was performed in this study, promotes an inductive process to coding and theme development from research data (Terry et al., 2017). Both authors familiarised themselves with the data and transcripts, noting content. In the research, NVivo was used to support the inductive process of identifying descriptive and interpretative coding levels. NVivo is qualitative research software that assists

Table 1. The Supervisors' Learning Community

\begin{tabular}{|c|c|}
\hline \multicolumn{2}{|c|}{ THE SUPERVISORS' LEARNING COMMUNITY } \\
\hline AIM & $\begin{array}{l}\text { To deepen the reflective capacity of the supervisors and create } \\
\text { a space to critically reflect on skills and interventions used in } \\
\text { supervision practice. }\end{array}$ \\
\hline TIMING & $\begin{array}{l}\text { 1. Critical reflection of recording } 1 \text { ( } 45 \text { mins) } \\
\text { 2. Critical reflection of recording } 2 \text { ( } 45 \text { mins }) \\
\text { Total for a session }=1.5 \text { hours }\end{array}$ \\
\hline PRIOR TO THE MEETING & $\begin{array}{l}\text { Step 1: OT Supervisor (presenters } 1 \text { and } 2 \text { ) record a supervision } \\
\text { session each. } \\
\text { Step 2: OT Supervisor chooses segment for critical reflection of } \\
\text { approx. } 15 \text { minutes. }\end{array}$ \\
\hline STRUCTURE OF EACH SESSION & $\begin{array}{l}\text { Step 3: Group meets, listens to the segment of the recording from } \\
\text { presenter } 1 . \\
\text { Step 4: In session presenter } 1 \text { gives a context to the recording and } \\
\text { supervision session and states what she/he was trying to achieve } \\
\text { during the recording segment. Presenter } 1 \text { then shares: } \\
\text { What they liked/strengths } \\
\text { What they would like to improve/areas for development } \\
\text { A question they are now considering } \\
\text { Step 5: The other group members then share, in turn: } \\
\text { Strengths (affirming statement) } \\
\text { Areas for development (extending statement) } \\
\text { The other group members reflect on how the presentation relates to, } \\
\text { or resonates with, them and/or their practice. } \\
\text { Step 6: Presenter } 1 \text { reflects on their responses from the group } \\
\text { *The process is repeated by presenter } 2 \text {. } \\
\text { *These discussions are recorded onto an audio-recorder }\end{array}$ \\
\hline
\end{tabular}


storing, managing and categorising information (Bazeley \& Jackson, 2013). Themes were developed from the codes, reviewed and tested for viability in developing a narrative from the data. The authors discussed the codes and themes on an ongoing basis and used thematic maps for deeper immersion into the data. The three themes generated from the discussions were deeper reflections on: supervisory skills / interventions; the structure of supervision; and working with emotion and trauma. The following section focuses on the value of the learning community for participants in improving reflective capacity in supervisory relationships and providing learning opportunities for the supervisors.

\section{Findings}

\section{Supervisory skills/interventions}

A first theme identified from the learning community sessions were the skills and interventions that the supervisor used, or would like to use, in their supervision. Despite being experienced supervisors, considerable uncertainty was identified around how to be present with supervisees in supervision and how to facilitate appropriate interventions.

\section{Supervisor presence}

The busy, and at times, trauma-laden OT environment was particularly challenging for the supervisors as they worked towards being active and present for supervisees. At times they recognised that they were not fully engaged in the supervision process. The spectrum of "being present" stretched the supervisors from being fully engaged and actively challenging, to taking a passive approach and allowing the supervisee to "run" with the session.

Abraham used a sledding metaphor, which may be an exciting activity, but can also be somewhat out of control. Supervision in the OT environment requires the supervisor to manage uncertainty, complexity and maintain focus.

You give people what they want and you don't really have to think. It is easy just to slide through a supervision session and go "my mind wasn't really in that one", it is easy to jump on a sled and go down the slope and you are fine. Whereas if you are doing it properly it probably is a bit of hard work, you actually have to think. (Abraham)

Using a different, fishing, metaphor, Abraham related how the supervisor needed to be alert to interrupting and responding to the supervisee's information to allow greater critical discussion. "Snapping the reel in every now and then" connects to engagement and remaining alert to the supervisee's agenda.

The active and engaged supervisor must be ready and attentive to respond to the immediacy of the material that the supervisee brings to the session. Penny discussed the tension of intervening in supervision to promote deeper reflection whilst also maintaining active engagement:

So if you let them go ... then do you lose meaningful points at which you could get them to expand even further ... if you don't interrupt ... they may as well be sitting in the room on their own. (Penny)

The learning community became a useful source of feedback and affirmation when they noted that the supervisor was fully present in the session.

You were still present with her, she hadn't lost you. You might have felt "Oh how do I bring it back?" but actually you were there because we heard you - "yes [pause] good [pause], oh okay [pause], yeah." (Penny)

I thought you validated it and that was good and ... you shouldn't try to be somebody else ... what you do, you do well. And you are spending the time 
with her and you are helping to explore. (Maria)

The distractions of a busy office and the multiple pressures on the supervisor made it difficult to remain present and focused. Each of the supervisors reflected on the challenges of managing a cluttered supervision space that was packed with administrative and line management responsibilities, leaving little space for critical reflection. Supervisor presence also requires shifting from current focus to a broader view looking at trends or themes that influence future decision making and preferred outcomes. This enables the supervisor to consider how the supervision space is used and encourage "super-vision".

It might be interesting to explore how that role looks around the ongoing lower level [social work support] moving away from that incident based [child protection intervention] stuff. (Elizabeth)

There is a lot still to be thought about, how much work does [the supervisee] do and at what point ... she shouldn't be doing much at all in actual fact. (Maria)

\section{Empowerment in decision-making}

The supervisors struggled with the quandary of how to facilitate a process where supervisees were supported and empowered, yet still challenged to think differently. The supervisors were often perceived as experts or, occasionally, parents, and recognised that this was not helpful for the professional development of the supervisee. Given the time-poor child protection context and pressure to ensure expediency, the supervisors felt cornered into giving supervisees the answers, rather than encouraging them to reflect on their own approach.

Because supervisees want the opinion of the supervisor I find it is the easiest way. They just want to ask someone a question and have an answer, but actually I can't answer a question about your own style and way of thinking [but] I can help you explore that. (Penny)

From hearing another supervisor's recording, Maria shared her thoughts on empowering her supervisees with, "it is okay for her to come in asking questions, but I would also get her to come up with the answer." She then reflected on her own ability and difficulties in her supervision of others: "My big thing is trying to enable people to do their own thinking, and that is easier said than done really."

Elizabeth reflected on her role as a mentor for young social workers, using the metaphor of a "mother duck" in the decisionmaking process, yet recognising that the social worker must achieve independence.

I think it is okay to be a mother duck for a little while ... when somebody is brand new and I could tell that she was really fragile in her work [and] was probably thinking "is this for me?" ... It is her confidence more. [But] she is not going to grow confidence if she is under my wing the whole time. (Elizabeth)

The supervisors identified the developmental lens required to challenge a supervisee to think and learn at different stages of their social work career. The needs of a new graduate were different from those of a seasoned social worker.

I think different social workers are at different places with being able to be reflective ... I think it is easier with the experienced ones to be able to ask some of those questions that gets them thinking about practice. (Maria)

The difference between supporting and challenging somebody [is] when you are at a certain level ... they should be able to handle the challenge ...It's a different mindset—you think differently when you know you are going to be challenged and it is a different outcome ... It is a complicated process to challenge someone, it is not easy. (Abraham) 


\section{Giving advice and developing strengths-based skills}

The supervisors debated the appropriateness of interrupting the supervisee's thinking by giving advice and the wish to develop more strengths-based questioning. The learning community assisted them to consider their own style of supervising and how to improve their skills.

Abraham acknowledged his uncertainty about delivering a "mini lecture" in a supervision discussion, running the risk of losing engagement with the supervisee and being seen as an expert. He expressed this as "a little bit preachy" with a level of judgement that it is bad to preach; however, the experience of the supervisor might well be highly valued by the supervisee.

The learning community affirmed for Abraham that he had successfully interrupted the supervisee's stream of consciousness in the conversation and then noted that "she really started thinking." The "preachy" disclosure from Abraham also demonstrates his trust and preparedness, despite his vulnerability, to share his practice with the learning community.

For other supervisors, like Elizabeth, importance was placed on utilising strengths-based skills to assist supervisees move past problem-saturated discussions and creating moments to engage in positive aspects of the work completed:

It is actually about having ideas about things to interject or, finding moments or a "sample" question or something like that like: "tell me something that you think has gone really well" I need some of those just to pull in. (Elizabeth)

When the group listened to this recorded segment from Elizabeth, it created deeper learning:

... after she had dumped all of that and you ... redirected her into, "so what's gone well?"... I'm going to take away that question about what has gone really well for you, and "what is something you are proud of?" Because I thought that was a really good question ... that is certainly a question I'm going to try. (Maria)

It was evident that the learning community were digging deeper and sharing their most difficult conversations with each other as the learning community developed. The tone of the discussions was changing and becoming strengths based.

\section{The structure of supervision}

The second theme from the learning community was the structure of supervision. A common concern identified was the administrative time required due to linemanagement accountabilities. This pervasive concern left the supervisors considering how it might be possible to create a reflective learning environment within supervision, when they felt so constrained by administrative and case responsibilities. The supervisors explained their pressing organisational responsibilities as supervisor managers:

I do think that the task centred (supervision) is relevant ... Sometimes you just have to know and it is impossible to do this work where there are KPIs ... without running through a caseload every so often, going "Okay actually where are you at with this?" (Penny)

Our organisation has lots of responsibilities around managing public money ... I need to be able to record that I have had those conversations about workload, annual leave ... and it has got to be recorded somewhere ... because if something crashes I need to be able to show that I've had those discussions ... I've learned from having my supervision audited when a supervisor did crash and when we had complaints. (Maria)

In hearing Maria, we became aware of the burden of administrative requirements, 
and Maria's concern to do her best for the organisation and to keep her supervisee and herself safe.

\section{Administration and case work}

The supervisors in the learning community had their own approaches to managing administration in the supervision space. For Maria, administration items were "jotted down" as the necessary priority and "getting that out of the way [first] because that is the boring stuff."

Maria also recognised the shortcuts that she would use in supervision with her supervisee to ensure large volumes of information were shared. This included labelling clients to enable recall and meant that there was little time for critical reflection:

We tend to use a lot more shortcuts in the way we talk than what either of us would during a usual supervision. It is more how we talk in the office rather than good reflective supervision. So tell me about mental health girl because I can't remember her name off the top of my head, but she knows who I mean. (Maria)

Whilst it was felt that the supervision space predominantly focused on administration and case work, it was also recognised that these conversations had become a safe and comfortable space. Creating space for critical reflection felt like uncharted terrain and not as comfortable for the supervisors.

I'm the problem, I am more comfortable really staying and just doing case work. [Case work] seems much more [safe] and easier ... if we start going deeper am I going to be out of my depth potentially? (Maria)

\section{Facilitating the structure}

Despite the time and administrative pressures faced by the supervisors, maintaining a meaningful focus to the session appeared problematic to the supervisors. Maria described supervisees using supervision as their "dumping ground" to offload their stream of issues and for Penny this "commandeered" the session. For Maria this needed to simply "start out with 'how are you?' and then move onto setting the agenda." The learning community highlighted for Penny the clarity of setting an agenda "and is it okay to leave stuff to another time. I am never quite sure particularly where to end supervision, because we have sat there for [up to] $2 \frac{1}{2}$ hours". Giving attention to agenda setting early on the session was agreed by the learning community as paramount to avoid drift.

By using the learning community to explore alternative ways of working, the supervisors were able to draw on their collective wisdom and develop confidence in their abilities to facilitate effective supervision. This started with the supervision contract:

We talk about it when we do our supervision contract: what are your expectations, what do you want, how are we going to resolve things if we are talking about a case and we disagree, how are we going to deal with difficult stuff, personal stuff? (Penny)

Setting an agenda became purposeful as Penny realised that "supervision is about the supervisee" and that "each [supervisee] gets to talk about things [they] want to talk about" and that "the supervisor needs to drive it." Elizabeth offered that "by asking [supervisees] at the beginning what they want [and whether this was] achieved by the end" gave the supervisor important feedback on the session's structure.

... you have to allow them to unpack ... and to keep facilitating that, otherwise you are leading and if you are leading then your thoughts really are the ones that are directing their practice. (Abraham)

\section{Working with emotion and trauma}

The supervisors discussed the emotion that they encountered during their sessions. Their 
supervisees were under extreme pressure, both personally and professionally, at times. The expression of emotion brought out conflicting feelings and responses from the learning community.

She was crying and I have a tendency not to ignore feelings by any stretch, but I kind of acknowledge them, but get to the root of the problem to get some perspective and sometimes is that the right way? No, sometimes it is depending on the situation. (Abraham)

The group went on to explore the nature of acknowledging emotions and empathising with supervisees further:

... where is it appropriate to empathise with the feelings of the person you are talking to? And going, "I know just how you feel because I feel the same," and where do you stay outside of that and hope that they don't feel like you are an unfeeling monster that just doesn't care. (Penny)

\section{Containing the shared experience of trauma}

The learning community acknowledged that the presentation of emotion by the supervisee can be projected from an experience that is so familiar to the supervisor that they, in turn, have difficulty containing their own feelings. The experience can be one of being retraumatised. The traumatic nature of the OT work requires a high level of resilience and the risk of traumatisation, directly or indirectly, is high amongst both supervisees and supervisors in the child protection environment.

The shared suffering or experience becomes difficult to navigate and is discussed in the learning community as a negative cycle. Penny says:

I don't know if it is helpful or not helpful for supervisees to know that we are just as if not more stressed than they are at any given time. Sometimes you just want to go "yeah we are in this together and it is just as terrible for me" and other times you just want to go "hang on let's just pretend to be above this" ... you just end up that circling the drain together ... and I don't know if that is helpful, but the temptation is there and you have to actually stop yourself from doing it or know when you are doing it. (Penny)

\section{Discussion: The value of the learning community}

Supervisors within statutory child protection organisations struggle to balance administrative requirements and obligations alongside a professional space that supports reflection and learning. The OT supervisors from the learning community described the cluttered supervision space and heavy expectations to meet various managerial demands. The description from the OT supervisors mirrors current criticisms from the Ombudsman (Boshier, 2020), the Office of the Children's Commissioner (OCC, 2020) and the Waitangi Tribunal (Waitangi Tribunal, 2021). These expectations have been related to procedure, risk and case management systems (Beddoe, 2010) at the expense of skills and time to deepen professional capacity that assists in working with families (Davys \& Beddoe, 2020). Such supervision practices align better with line-management and, arguably, do not support the development of the social worker's personal and professional practice (Morrison, 2001).

Reflective supervision becomes pivotal for social workers to develop critical reflection in their practice (Rankine, 2018). Within the current neoliberal environment, managerial and organisational issues weigh heavily on practitioners' minds and dominate work commitments. A learning community provides practitioners time to engage in practice reflection with colleagues (Davys et al., 2019). Spaces for supervisors to regularly review and discuss how they "do" reflective 
supervision need to be amplified in ongoing professional routines. Reflective supervision, underpinned by critical reflection, provides the vision for improved practice for children and families, especially Māori.

The learning community created a new experience for supervisors that did not previously exist in their workspace.

Participants were able put aside their day-today managerial routines and reflect further on the skills and interventions, the structure of the supervision session and how to effectively work with emotion and trauma. Furthermore, the learning community provided the space for supervisors to: 1) reflect on practice together through hearing and listening to their own and others' supervision experiences; 2) engage in feedback and gather personal reflections that challenged existing practices; and 3) express vulnerability and be supported by colleagues through the learning community process which led to strengthened working relationships. Such outcomes are consistent with previous research of learning communities (Davys et al., 2019). Throughout the learning community experience, the supervisors reflected on the valuable time away from the social work front line and recognised the critical importance of being open to challenge so that they could learn and grow.

One thing was ... moving out of the safe zone, you know, just for myself as a supervisor and being challenged about that and where the growth [is] happening and ... reminding myself about that so I now carry that with me again ... and I need not be worried about it. Just cross that threshold and see what happens. (Maria)

Moving out of the safe zone became a catch-phrase for the learning community to critically reflect and challenge one another. As illustrated in Figure 2, challenges promoted growth and experience for the supervisors through reflection and integrated learning. Through evaluation and feedback at several points, the learning community extends traditional understandings of learning cycles and experiential learning (Knowles, 1990; Kolb, 2014).

The cyclical nature of learning, not only creates growth for the supervisor, but promotes synergy and growth for the entire

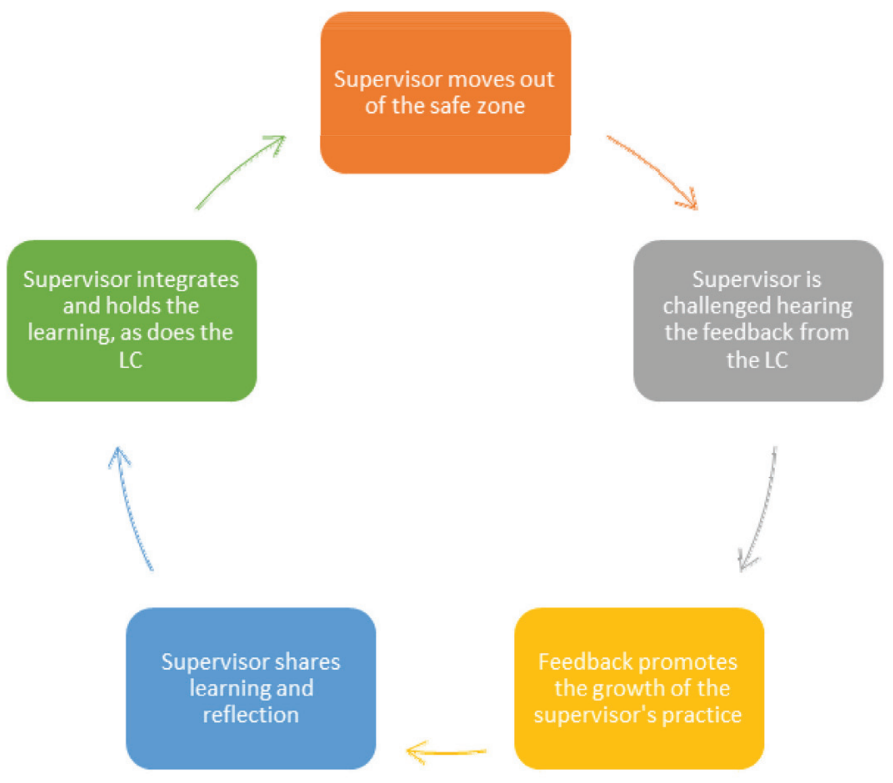

Figure 2. The Reflection and Learning Cycle of the Supervisor 
learning community:

I am constantly learning things about myself even though it is somebody else's session. I constantly think ... I've been there ... I miss opportunities all the time and it is just such a good reminder to me when I hear somebody else doing the same. (Penny)

The learning community is isomorphic in nature as changes can then be replicated in other relationships (Davys \& Beddoe, 2020). There is the potential for the supervisors' learning to then be transported into their supervision sessions with supervisees and consequently, an impact on practice outcomes through collaborative decision making. From the perspective of critical reflection, practice is reconstructed through these new strategies and generates agency (Fook \& Gardner, 2007).

For critical reflection and learning to occur, the practitioner requires the time to analyse events, interactions and plans (Davys \& Beddoe, 2020). In order that social work maintains its professional integrity, the exploration of structural barriers and risk factors affecting children and families is essential. This process is particularly transformational, unsettling and perhaps uncomfortable when done with the support of others (Carroll, 2010). Maria acknowledged the vulnerability required to move out of the safe zone to achieve rewards.

[The learning community] is a unique opportunity really isn't it like you are putting yourself in a vulnerable position but there are rewards from that just getting the feedback. The suggestions and also the things you come away feeling not quite so bad as you think you might have. (Maria)

The reciprocal sharing of learning and the supervisors' preparedness to be vulnerable, was also reported to strengthen the working relationship of the supervisors. Abraham stated he "enjoyed every minute of it" as "you are continually picking up stuff - I have learnt from everybody."

I think it strengthens our relationships too, because we come to this place of vulnerability ... that actually is like a gift ... for me I felt that has been one of the biggest benefits is feeling like developing more trusting relationships because you do have to trust your colleagues and put yourself on the table. (Maria)

For many supervisors there may be a feeling of isolation as reviewing and evaluating supervision practice for learning and development has been recognised as rare alongside being extremely advantageous if it is undertaken (Davys et al., 2019; Wilkins et al., 2018). Abraham concurred: “you don't get to hear other people's supervision sessions and so it has been nice to have it affirmed" claiming that "those [admin] responsibilities get in the way and [occupy] so much time. I don't think you can get to this stuff that you need to get to ... it should be professional supervision." Critical to current social work practice in OT is the space to review supervision practice and explore wider environmental issues impacting on social work decision making involving whānau Māori (Waitangi Tribunal, 2021). The learning community provides the opportunity for supervisors and social workers to collaboratively engage in these key practice conversations.

The supervisors concurred with the study's aim that the learning community space deepened their reflective capacity. This process had a transformative effect which challenged the way the supervisors viewed their role towards facilitating reflective supervision and, moreover, how a learning culture could be promoted in the organisation. In doing so, supervisors can develop critical conversations around social justice and the impact of practice decision making on Māori. Abraham stated that "[learning communities] is the development stuff that so many supervisors in this place 
[OT] need" and that "it would be a lot more effective if this sort of thing was rolled out across the country." Such initiatives like the development of learning communities, Maria felt, would "improve the practice onsite [and have] a flow-on effect." Such a flow-on effect from reflective spaces can generate intervention and the development of antioppressive practice (Baines, 2017) —an area desperately needed for partnerships with Māori.

In social work, learning is seen as life-long. To aspire to this, individual practitioners need to take responsibility for their own professional development in supervision. The question for the learning community was how to juggle this commitment alongside managerial risk and time constraints. Penny acknowledged the espoused commitment to learning in her organisation and that it had to start with her personal accountability towards developing her own critical reflection and promoting social justice for the communities she worked with:

So there is a very strong push in this organisation for professional development to happen for staff [and] that is the supervisor's responsibility ... [But] nobody else is taking care of my professional development except for me. (Penny)

\section{Limitations of study}

Engaging in a learning community with peers requires a high level of trust and a preparedness to be vulnerable. In addition, members of the learning community need to hold a commitment to regularly meet and put aside other organisational demands. Whilst this learning community comprised experienced supervisors and positive experiences of knowing one another beforehand, future learning communities may not have this experience. Mistrust, unconscious and conscious individual and group agendas would lead to degenerate and negative experiences of a learning community-this would not be conducive to reflective processes occurring. Developing a group agreement at the commencement of the learning community is one important avenue that provides structure and agreed ways of working.

One participant in the learning community had a hearing impairment and this was a factor that required group consideration. Therefore, a decision was reached that audio recordings were shared prior to the session so that everyone could engage equally when the learning community met. This was a cue for the authors to consider accessibility issues that might impact on future learning community groups.

The supervisors' experiences and reflections are exclusive to the learning community in this study. The learning community comprised only four participants. Therefore, views related to cultural diversity, understandings of critical reflection and participant experience were not captured on a significant scale. The collection of data may not represent other OT offices or statutory social work organisations so claims of transferability and generalisability are limited. Despite the small sample presented, this study contributes towards the evidence base of supervision literature in social work practice through an Aotearoa New Zealand lens. More importantly, the study provides a pathway in statutory social work, such as OT, for the future development of effective learning communities. Such spaces provide critically reflective conversations to emerge that challenge existing structural and power issues in supervision and explore alternatives to social work practice with families.

\section{Conclusion}

The learning community offers a proven approach to building reflective supervision capacity in statutory social work. The implementation of learning communities across the social work sector promotes practice efficacy and could provide a response to the criticisms levelled at OT, 
from the OCC, the Ombudsman and the Waitangi Tribunal. Within the bureaucratic and crisis-driven environment of statutory child protection, social workers need reflective supervision to learn, critically reflect and develop robust decision making in their practice with children and families. Reports and literature in child protection nationally (and internationally) point to such recommendations and requirements within social work practice on a continual basis. The creation of learning communities could improve practice and be a regular part of professional practice routines. Whilst a focus for on-going training might predominantly be on frontline social workers, their supervisors also need training to develop and ensure that their support of social workers is competent, safe and accountable. This study has demonstrated that a learning community provides an ideal protected space for evaluating, critiquing and developing supportive practice within a busy statutory environment.

\section{Acknowledgements}

Sophia de Fossard and Laia Bolibar Navarro for their assistance in the analysis of the data.

Accepted 18 July 2021

Published 1 September 2021

\section{References}

Baginsky, M., Moriarty, J., Manthorpe, J., Stevens, M., Maclnnes, T., \& Nagendran, T. (2010). Social workers' workload survey: Messages from the frontline: Findings from the 2009 survey and interviews with senior managers. Department for Education.

Baines, D. (2017). Doing anti-oppressive practice. Social justice social work. Fernwood.

Bazeley, P., \& Jackson, K. (2013). Qualitative data analysis with NVivo. SAGE.

Beddoe, L. (2010). Surveillance or reflection: Professional supervision in "the risk society." British Journal of Social Work, 4O(4), 1279-1296.

Beddoe, L. (2016). Supervision in social work in Aotearoa New Zealand: Challenges in changing contexts. The Clinical Supervisor, 35(2), 156-174.

Beddoe, L., Davys, A., \& Adamson, C. (2014). Building resilient practitioners: Definitions and practitioner understandings. The British Journal of Social Work, 44(3), 522-541. https://doi.org/10.1093/bjsw/bcs142
Beddoe, L., Fouché, C., Bartley, A., \& Harington, P. (2012). Migrant social workers' experience in New Zealand: Education and supervision issues. Social Work Education, 31(8), 1012-1031.

Bernard, J. M., \& Goodyear, R. K. (2009). Fundamentals of clinical supervision. Pearson.

Bhaskar, R. (1979). A realist theory of science. Harvester Press.

Boshier, P. (2020). A matter of urgency: Investigation report into policies, practices and procedures for the removal of newborn pēpi by Oranga Tamariki, Ministry for Children. https://www.ombudsman.parliament.nz/sites/default/ files/2020-10/He_Take_K\%C5\%8Dhukihuki_A_Matter_ of_Urgency-OT_Report-102020-DIGITAL.pdf

Bradbury-Jones, C. (2013). Refocusing child protection supervision: An innovative approach to supporting practitioners. Child Care in Practice, 19(3), 253-266.

Carpenter, J., Webb, C., Bostock, L., \& Coomber, C. (2012). Effective supervision in social work and social care. Research Briefing 43. Social Care Institute for Excellence.

Carroll, M. (2010). Supervision: Critical reflection for transformational learning (Part 2). The Clinical Supervisor, 29(1), 1-19.

Crotty, M. (1998). The foundations of social research. Meaning and perspective in the research process. Allen and Unwin.

Davys, A., \& Beddoe, L. (2020). Best practice in professional supervision: A guide for the helping professions (2nd ed.). Jessica Kingsley.

Davys, A., Howard, F., Rankine, M., \& Thompson, A. (2019). Supervision under the microscope: Critical conversations in a learning community. Practice, 31(5), 1-16. doi:10.10 80/09503153.2018.1558196

Davys, A., May, J., Burns, B., \& O'Connell, M. (2017). Evaluating social work supervision. Aotearoa New Zealand Social Work, 29(3), 108-121. doi.org/10.11157/ anzswj-vol29iss3id314

Fook, J. (2011). Developing critical reflection as a research method. In J. Higgs, A. Titchen, D. Horsfall, \& D. Bridges (Eds.), Creative spaces for qualitative researching (pp. 55-64). Sense Publishers.

Fook, J., \& Gardner, F. (2007). Practising critical reflection: A resource handbook. Open University Press.

Hill, H. R. M., Crowe, T. P., \& Gonsalvez, C. J. (2016). Reflective dialogue in clinical supervision: A pilot study involving collaborative review of supervision videos. Psychotherapy Research, 26(3), 263-278.

Hyslop, I. (2017). Child protection in New Zealand: A history of the future. British Journal of Social Work, 47, 1800-1817.

Kelly, S., \& Green, T. (2019). Seeing more, better sight: Using an interprofessional model of supervision to support reflective child protection practice within the health setting. British Journal of Social Work. doi:10.1093/bjsw/bcz030

Knowles, M. S. (1990). The adult learner: A neglected species (building blocks of human potential). Gulf Publishing.

Kolb, D. A. (2014). Experiential learning: Experience as the source of learning and development. FT Press. 
Mor Barak, M. E., Travis, D. J., Pyun, H., \& Xie, B. (2009). The impact of supervision on worker outcomes: A metaanalysis. Social Service Review, 83(1), 3-32.

Morley, C. (2013). Some methodological and ethical tensions in using critical reflection as a research methodology. In J. Fook \& F. Gardner (Eds.), Critical reflection in context. Applications in health and social care (pp. 166-178). Routledge.

Morrison, T. (2001). Staff supervision in social care: Making a real difference for staff and service users. Pavilion.

Munford, R., \& Sanders. J. (2008). Building action focused research in social care organisations. Educational Action Research, 16 (1), 9-20. doi:10.1080/09650790701833071

Oranga Tamariki, Ministry for Children. (2017). Professional supervision: Policy and standards. https://practice. orangatamariki.govt.nz/assets/practice/use-professionalsupervision/5139fa22bf/professional-supervision-policyand-standards.pdf

Nickson, A., Carter, M., \& Francis, A. (2020). Supervision and professional development in social work practice. Sage.

Noble, C., Gray, M., \& Johnston, L. (2016). Critical supervision for the human services: $A$ social model to promote learning and value-based practice. Jessica Kingsley.

O'Donoghue, K. (2008). Towards improving social work supervision in Aotearoa New Zealand. Aotearoa New Zealand Social Work Review, 20(1), 10-21.

O'Donoghue, K., \& Tsui, M.-s. (2011). Towards a professional supervision culture: The development of social work supervision in Aotearoa New Zealand. International Social Work, 55(1), 5-28. doi:10.1177/0020872810396109

Office of the Children's Commissioner. (2020). Te Kuku O Te Manawa. https://www.occ.org.nz/assets/Uploads/ Te-Kuku-O-Te-Manawa-Report-2-OCC.pdf

Rankine, M. (2017). Making connections: A practice model for reflective supervision. Aotearoa New Zealand Social Work, 29(3), 66-78.

Rankine, M. (2018). How critical are we? Revitalising critical reflection in supervision. Advances in Social Work \& Welfare Education, 20(2), 31-46.

Ruch, G., West, L., Ross, F., Fook, J., \& Collington, V. (2015). Researching critical reflection: Multidisciplinary perspectives. Routledge.

Stoll, L., Bolam, L., McMahon, A., Wallace, M., \& Thomas, S. (2006). Professional learning communities: A review of the literature. Journal of Educational Change, 7(4), 221-258.

Terry, G., Hayfield, N., Clarke, V., \& Braun, V. (2017). Thematic analysis. In W. Stainton Rogers \& C. Willig (Eds.), The SAGE handbook of qualitative research in psychology (pp. 17-37). SAGE Publications.

Waitangi Tribunal. (2021). He Pāharakeke, he Rito Whakakīkinga Whāruarua. Oranga Tamariki Urgent Inquiry. https://forms.justice.govt.nz/search/Documents/ WT/wt_DOC_171027305/He\%20Paharakeke\%20W.pdf

Wilkins, D., Forrester, D., \& Grant, L. (2017). What happens in child and family social work supervision? Child and Family Social Work, 22(2), 942-951.

Wilkins, D., Khan, M., Stabler, L., Newlands, F., \& Mcdonnell, J. (2018). Evaluating the quality of social work supervision in UK children's services: Comparing self-report and independent observations. Clinical Social Work Journal, 46, 350-360. doi.org/10.1007/s10615018-0680-7 